\title{
Laboratory Mix Design of Asphalt Mixture Containing Reclaimed Material
}

\author{
Davide Lo Presti, ${ }^{1}$ Rawid Khan, ${ }^{2}$ Norhidayah Abdul Hassan, ${ }^{3}$ \\ Gordon Airey, ${ }^{1}$ and Andrew Collop ${ }^{4}$ \\ ${ }^{1}$ Nottingham Transportation Engineering Centre, University of Nottingham, NG7 2RD, UK \\ ${ }^{2}$ University of Engineering and Technology, Peshawar 25000, Pakistan \\ ${ }^{3}$ Universiti Teknologi Malaysia, 81310, Malaysia \\ ${ }^{4}$ De Montfort University, Leicester LE1 9BH, UK
}

Correspondence should be addressed to Rawid Khan; rawid806@gmail.com

Received 7 May 2013; Accepted 22 October 2013; Published 14 January 2014

Academic Editor: Liyuan Sheng

Copyright (C) 2014 Davide Lo Presti et al. This is an open access article distributed under the Creative Commons Attribution License, which permits unrestricted use, distribution, and reproduction in any medium, provided the original work is properly cited.

\begin{abstract}
This paper presents a study on the production of asphalt test specimens in the laboratory containing reclaimed asphalt. The mixtures considered were stone mastic asphalt concrete mixtures containing up to $30 \%$ of reclaimed asphalt. Specimens were compacted to the reference density obtained from the Marshall mix design. Gyration compaction method was used for preparing specimens for the experimental programme, while coring and cutting methods and X-ray computed tomography (CT) were used to investigate the change in properties within the specimens and to validate the selected methodology. The study concluded that gyratory compaction is suitable to produce homogeneous test specimens also for mixtures containing high amount of reclaimed asphalt. Nevertheless, preliminary trials for each material are mandatory, as well as final coring and trimming of the specimens due to side effects.
\end{abstract}

\section{Introduction}

The use of gyratory compactor for producing asphalt mixture specimens has been used preferably over other methods such as the Marshall hammer largely on the basis that it has a better control on compaction which provides a reliable way to evaluate the density of the mix design. The gyratory compaction process changes by varying the number of gyrations. The angle of the plates and the pressure are fixed by the manufacturer of the gyratory compactor according to EN 12697-31:2007 [1]. The required target density (for the design air voids) is fixed as input and compactor automatically apply certain number of gyrations to achieve the required density. The size of gyratory mould, uniformity over the sample, and the height/diameter ratio influence the air voids distribution and the density. In addition, the vertical air void distribution within the gyratory compacted specimen is different between the core section and the section close to the circumference. Higher air voids are observed in the circumference and evenly distributed compared to those within the core section [2].
Hence, specimen manufactured through gyratory compactor usually presents issues concerning the specimen's homogeneity [3]. This arises from the fact that two replicates from nominally identical test specimens sometimes show a variation in their performance and hence the requirement to produce at least three replicates for verification. A homogeneous specimen has the same proportions or properties throughout its volume to create a consistent mixture for testing purposes and performance evaluation. Although air voids possess no mechanical strength, their distribution is crucial in determining the overall response of the material [4]. Therefore, the variation in the performance of specimen replicates with the same total air voids content could be accounted for by the difference in air void distribution over the height and the width of the specimen.

The variation of air void distribution in gyratory compacted specimens has been reported by a few researchers. For example, the air voids were characterised using X-ray $\mathrm{CT}$ and image analysis technique and compared with the 
air voids content determined in the laboratory $[5,6]$. Xray $\mathrm{CT}$ has demonstrated considerable promise to efficiently characterise the microstructure of asphalt mixture where the specimen can be nondestructively investigated in different planes whilst still intact for further mechanical testing [7]. A virtual cutting technique can be used to obtain the crosssections in different orientations. Studies by Wang et al. [8,9] and Masad et al. [10] indicated that the air void distribution in gyratory compacted specimens with the ratio of height to the diameter being 1 followed a "bathtub shape" where higher air voids were concentrated at the top and bottom specimen. In the middle section, the air voids were found to be less and fairly distributed over the height. This shape was more pronounced at higher compaction efforts. Another study by Tashman et al. [11], using compacted specimens with the height and diameter ratio being more than 1, reported a different air voids distribution. A higher void content was found in the middle compared to the top and bottom sections. This demonstrates that the specimen height and diameter play a significant role in controlling the air voids distribution "as well as the variation in density." The nonuniformity of the air void distribution analysis revealed that there is a need to prepare homogeneous laboratory specimens. In this paper, the laboratory specimen fabrication technique using gyratory compactor was studied to produce a homogeneous compacted specimen with uniform air voids distribution. This is important for preparing a good mix design for mechanical testing and modelling purpose. Specimens with different dimensions in height and diameter were prepared. The specimen's homogeneity was investigated using X-ray CT and compared to the density determined in the laboratory. Reclaimed asphalt was added to the mixture and compared with the virgin mixture to assess the effect of RA addition on specimen properties.

\section{Materials}

Two stone mastic asphalts have been used in this research: a virgin mixture (V-Mix) and a mixture containing 30\% reclaimed asphalt (RA-Mix). Both mixtures were designed with similar grading curve (Figure 1) and using binders with similar physical properties ( $\mathrm{PmB}$ 25/55-55A). Their properties are summarised as in Table 1.

\section{Samples Preparation and Compaction Procedures}

Specimens were prepared to achieve a target reference density and air void content that was obtained using a previous Marshall mix design procedure. The specimens were compacted using the gyratory compactor according to EN 12697-31:2007. The details of compaction are as follows.

3.1. Preparation of Test Portions for Gyratory Compaction. The asphalt mix was placed in an oven at a temperature of $115^{\circ} \mathrm{C}\left( \pm 5^{\circ} \mathrm{C}\right)$, and a suitable heating time was selected from observation such that it becomes loose and could be easily divided into portions. Each test portion was placed in

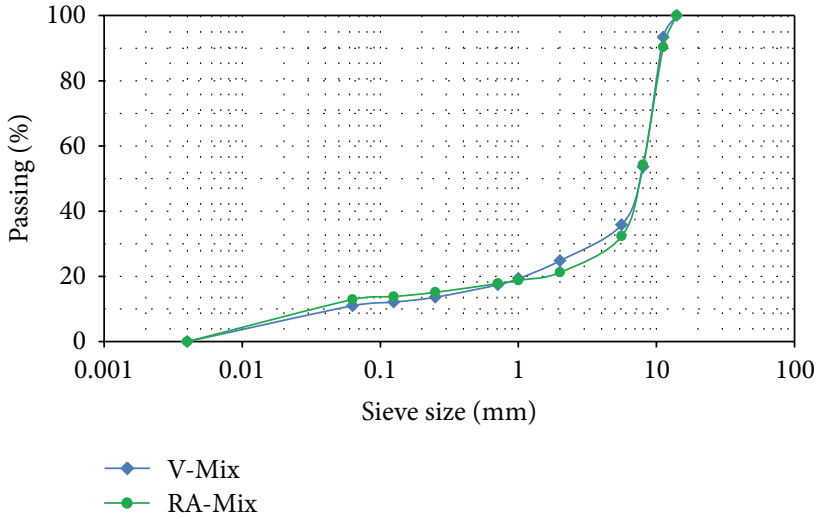

FIgURE 1: Aggregate grading curves of V-Mix and RA-Mix.

a smaller metal container (a volume of 2 litres is appropriate for the amount of one test portion) which was covered and stored at room temperature. Specimens were compacted between 1 and 3 days after storing.

3.2. Gyratory Compaction Procedure. The specimens were compacted using the gyratory compactor according to EN 12697-31:2007 and based on a procedure specifically developed for gyratory compaction of reclaimed asphalt mixes [12]. For all mixes, the asphalt was placed in an oven at $165^{\circ} \mathrm{C}$ $\left( \pm 5^{\circ} \mathrm{C}\right)$ for approximately 2 hours. After the temperature within the mix had dropped to $150^{\circ} \mathrm{C}$, it was manually stirred and then the preheated mould was filled with the mixture. The temperature of the mixture within the mould was then measured, and when it reached $145^{\circ} \mathrm{C}\left( \pm 5^{\circ} \mathrm{C}\right)$, compaction was started using the following standard conditions:

(i) internal angle: $0.82^{\circ}$,

(ii) compaction pressure: $600 \mathrm{kPa}$,

(iii) speed of rotation: 30 gyrations $/ \mathrm{min}$,

(iv) target density variable (parameters from plant were used; for consistent dimensions of specimens, the number of gyrations varied from the assumed 200 gyrations),

(v) diameter: 100 and $150 \mathrm{~mm}$.

\section{Compaction Procedure to Achieve Homogenous Air Void Distribution}

This study aims at producing homogenous cylindrical test specimens, for both virgin and reclaimed asphalt mixes, with $H / D$ ratio equal to 1 and fixed value of target air void content. In order to achieve this, the compaction of several specimens has been followed by the air voids content determination following buoyancy test (BS EN 12697-6:2003) and the air voids distribution by using X-ray CT scanning and image analysis techniques.

4.1. Specimens Compaction. The gyratory compactor offers the possibility of producing specimens with a diameter of 
TABle 1: Properties of V-Mix and RA-Mix.

\begin{tabular}{lccccc}
\hline Mix type & $\begin{array}{c}\text { Maximum } \\
\text { density }\end{array}$ & Binder content & $\begin{array}{c}\text { Binder Pen } \\
(\text { EN 1426) }\end{array}$ & $\begin{array}{c}\text { Binder SP (EN 1427) } \\
\text { Viscosity at 150 }{ }^{\circ} \mathrm{C} \\
(\mathrm{EN} \mathrm{13302)}\end{array}$ \\
\hline V-Mix SMA 11 S (0\% RA) & $2454 \mathrm{~g} / \mathrm{cm}^{3}$ & $6.5 \%$ & $30 \mathrm{dmm}$ & $64.2^{\circ} \mathrm{C}$ & $0.63 \mathrm{~Pa} . \mathrm{s}^{\circ}$ \\
RA-Mix SMA 11 S (30\% RA) & $2485 \mathrm{~g} / \mathrm{cm}^{3}$ & $7.2 \%$ & $21 \mathrm{dmm}$ & $70.8^{\circ} \mathrm{C}$ & $1.06 \mathrm{~Pa} . \mathrm{s}^{\circ}$ \\
\hline
\end{tabular}

TABLE 2: Details of the gyratory compacted specimens.

\begin{tabular}{|c|c|c|c|c|c|c|}
\hline Type & Sample & Diameter, $D(\mathrm{~mm})$ & Height, $H(\mathrm{~mm})$ & Target density $\left(\mathrm{kg} / \mathrm{m}^{3}\right)$ & Target air voids (\%) & Mass of sample (g) \\
\hline \multirow{3}{*}{ V-Mix } & $\mathrm{A} 0$ & 100 & 100 & 2391 & 2.6 & 1883 \\
\hline & $\mathrm{A} 1$ & 100 & 150 & 2391 & 2.6 & 2824 \\
\hline & $\mathrm{A} 2$ & 150 & 150 & 2391 & 2.6 & 6355 \\
\hline \multirow{3}{*}{ RA-Mix } & B0 & 100 & 100 & 2420 & 2.6 & 1905 \\
\hline & $\mathrm{B} 1$ & 100 & 150 & 2420 & 2.6 & 2857 \\
\hline & B2 & 150 & 150 & 2420 & 2.6 & 6430 \\
\hline
\end{tabular}

TABLE 3: Details of air voids content before and after trimming and coring.

\begin{tabular}{|c|c|c|c|c|c|c|c|}
\hline \multirow{2}{*}{ Type } & \multirow{2}{*}{ Sample } & \multirow{2}{*}{ Specimen $(H / D)$} & \multicolumn{2}{|c|}{ Core size } & \multirow{2}{*}{ Air voids ${ }_{\text {before }}(\%)$} & \multirow{2}{*}{ Target density $\left(\mathrm{kg} / \mathrm{m}^{3}\right)$} & \multirow{2}{*}{ Air voids $_{\text {after }}(\%)$} \\
\hline & & & Diameter $(\mathrm{mm})$ & Height (mm) & & & \\
\hline \multirow{3}{*}{ V-Mix } & A0 & $100 / 100$ & 100 & 100 & 2.6 & 2384 & 2.9 \\
\hline & Core A1 & $150 / 100$ & 100 & 100 & 2.6 & 2427 & 4.0 \\
\hline & Core A2 & $150 / 150$ & 100 & 100 & 2.6 & 2455 & 0.2 \\
\hline \multirow{3}{*}{ RA-Mix } & B0 & $100 / 100$ & 100 & 100 & 2.6 & 2390 & 3.8 \\
\hline & Core B1 & $150 / 100$ & 100 & 100 & 2.6 & 2370 & 4.5 \\
\hline & Core B2 & $150 / 150$ & 100 & 100 & 2.6 & 2470 & 0.6 \\
\hline
\end{tabular}

$100 \mathrm{~mm}$ and $150 \mathrm{~mm}$ with a $H / D$ ratio variable up to 1.5 . In order to obtain an optimized procedure, three types of specimens were compacted and analysed as follows.

4.1.1. Specimen $0(H / D<1)$. Specimens with exact dimension of $D=100 \mathrm{~mm}$ and $H=100 \mathrm{~mm}$ were compacted and then the density and air void content were determined using sealed specimens method (BS EN 12697-6:2003). It was noted the specimens achieved the target density and air voids content very well, but due to the angle of the plates set for the compaction $\left(0.25^{\circ}\right)$, the top and bottom surfaces of the specimens were not flat. And as per the standard procedure (EN 12697-31:2007), trimming procedure was, therefore, mandatory to obtain specimens suitable for testing. Nevertheless, this causes net specimen's height of less than $100 \mathrm{~mm}$ which makes the final ratio of height and diameter less than 1 .

Details of the designed gyratory compacted specimens are summarised in Table 2. Three replicates were prepared for each designed specimen to achieve the target air voids content of $2.6 \%$. Detail of the density after compaction and cutting is summarised in Table 3.

4.1.2. Specimens 1 and $2(H / D=1)$. In order to obtain suitable test specimens having a $H / D$ ratio equal to 1 , specimens with dimensions $100 \mathrm{~mm} / 150 \mathrm{~mm}$ and $150 \mathrm{~mm} / 150 \mathrm{~mm}$ were prepared (Table 2 ). These were then trimmed and cored to achieve the target dimensions (Figure 2). It was found that, after trimming, specimens 1 and 2 had higher and lower air voids content, respectively, though the target air void content was achieved. This shows a nonuniform distribution of voids (Table 3).

It was observed during compaction that the reclaimed asphalt mixes were harder to compact. At similar gyratory pressure, the number of gyros needed to compact reclaimed asphalt specimens was significantly higher than those necessary to compact the virgin mixture.

4.2. X-Ray CT Scanning. X-ray CT system (Venlo H -350/ 225) was used for scanning the specimens. The $350 \mathrm{kV}$ source was used to obtain the 2D images (slices). Slices were taken at $1 \mathrm{~mm}$ intervals along height of the specimen. The X-ray system used has resolution of 83 micron; that is, it can detect object/voids smaller up to $0.083 \mathrm{~mm}$ size. It was observed during scanning that some of the images had errors image due to scanning artifacts (beam hardening, ring artifacts) and partial volume effects.

Beam hardening results in nonuniform brightness in the $\mathrm{X}$-ray images, typically either dark in the centre and bright in edges or dark at the edges and bright in the centre. Beam hardening was eliminated by using/adjusting both the source and back filters. Some partial and full rings were found on the image during rotation of the sample while scanning. This is due to a shift in the output of the detector which occurs on every $\mathrm{X}$-ray which gives anomalous $\mathrm{X}$-ray values 

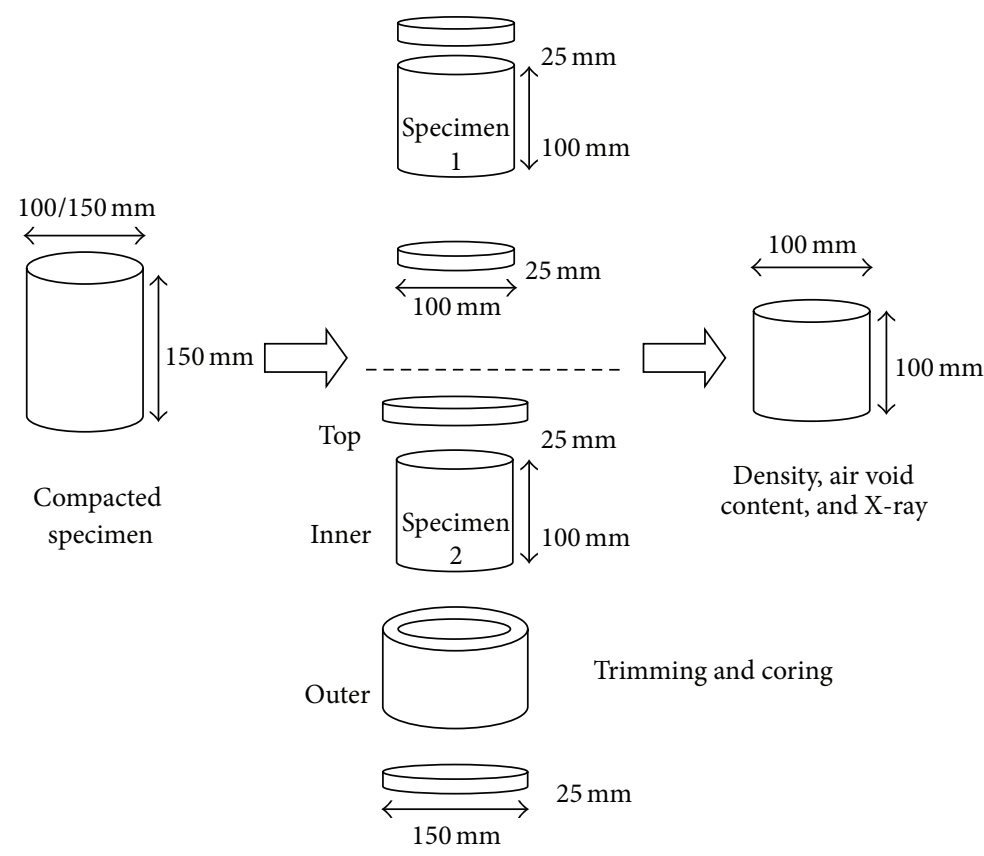

FIgURE 2: Trimming and coring works of (100/100) specimen from specimens 1 and 2.

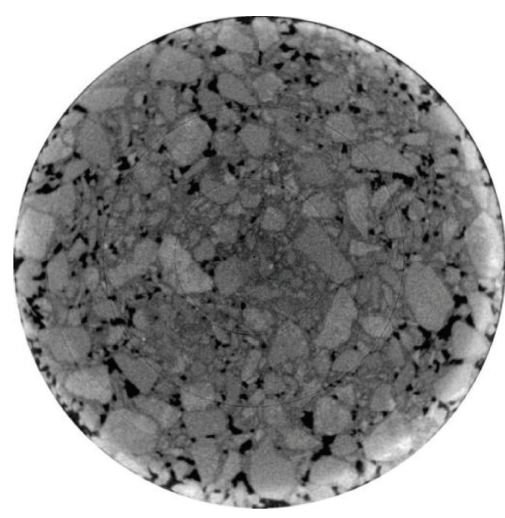

(a)

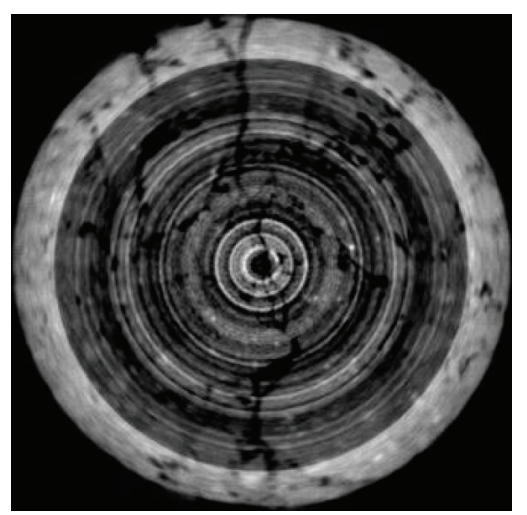

(c)

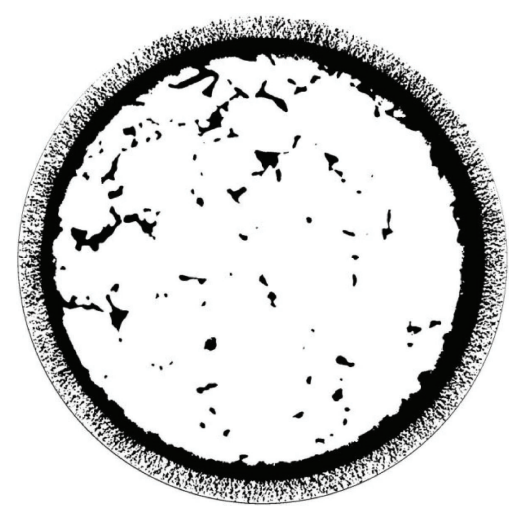

(b)

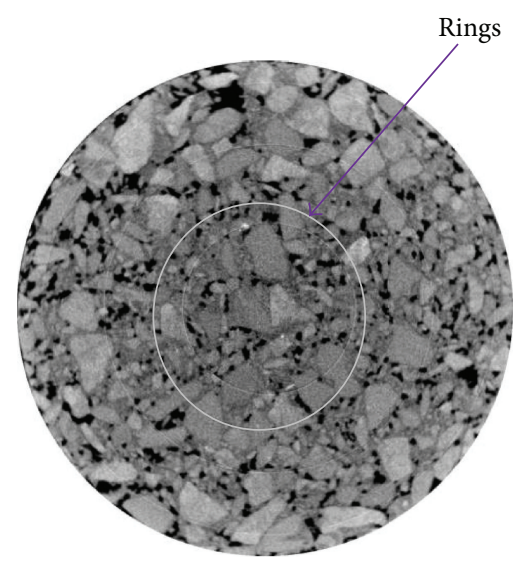

(d)

FIGURE 3: (a) Brightness due to beam hardening; (b) the black outer ring selected as part of air void; (c) high ring artifacts; (d) low ring artifacts. 


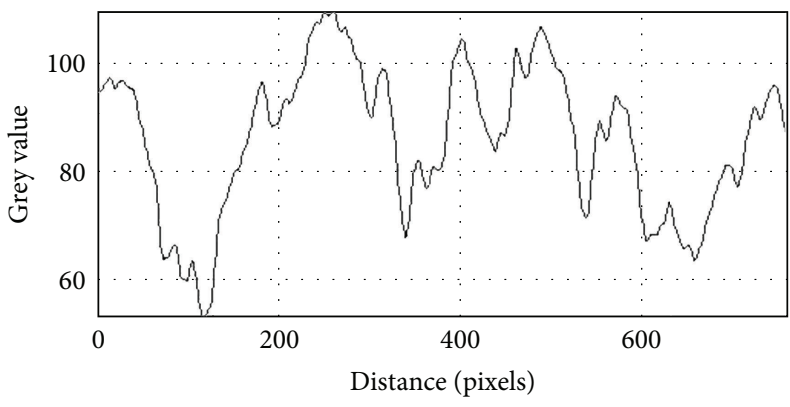

(a)

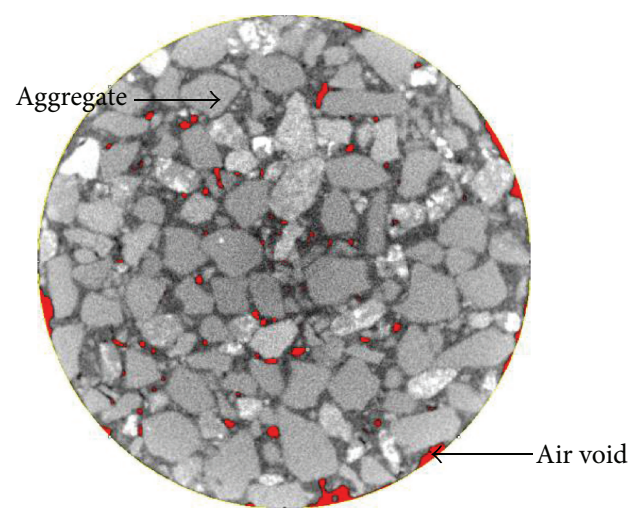

(b)

FIgURE 4: (a) Plot of grey value profile in asphalt mixture; (b) threshold image showing air voids in compacted asphalt mixture.

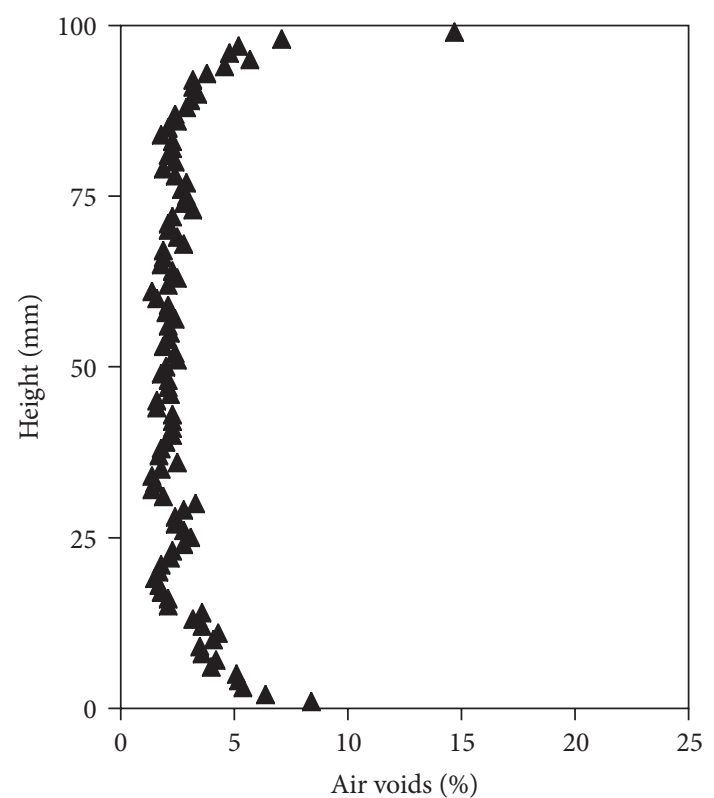

(a)

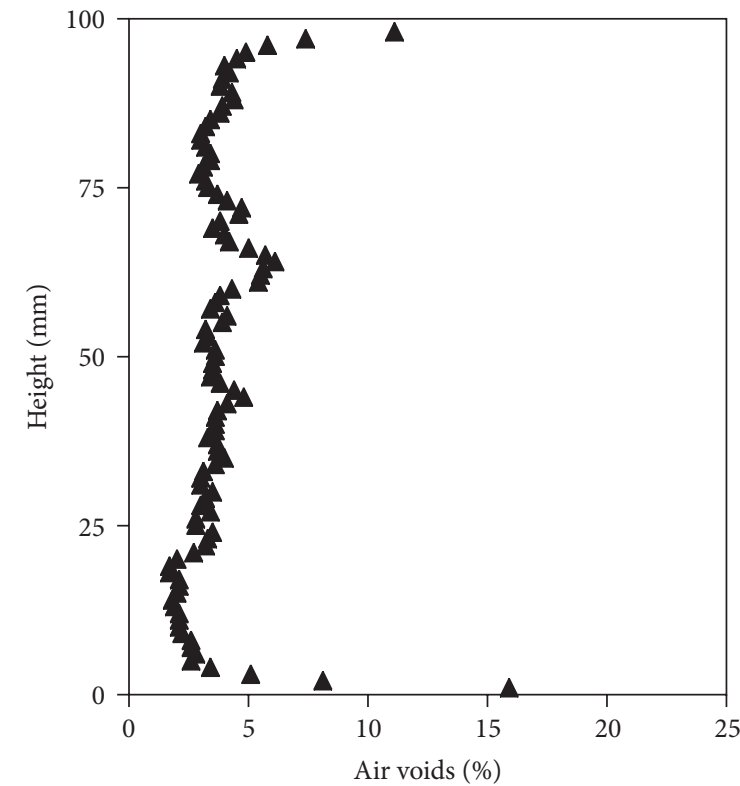

(b)

FIgURE 5: Air voids distribution in $100 \mathrm{~mm} \times 100 \mathrm{~mm}$ specimens for (a) V-Mix and (b) RA-Mix.

at the same point in the line array with every radiograph. It occurs because of the sensitivity of the detector to beam hardness (energy of the beam) (Figure 3) [13].

In X-ray images of asphalt, some of the pixels were found comprising part aggregate and part air void or mastic. For image analysis, every pixel in the X-ray image is either considered as aggregate, mastic, or air void. In the case of a pixel divided between two or three different components this is called a partial volume effect. The partial volume effect relates to the data for individual constituents within an asphalt mixture and was corrected in analysis.

4.3. Image Analysis. After scanning the specimens, $2 \mathrm{D}$ images (scans) were collected in image J and VG Studio Max, the image analysis tools, the images were trimmed, and defects were removed. The images were digitized into 256 levels with each pixel assigned a value from 0 to 255 where zero represents the black portion of the image and 255 represents the white portion. The resolution of the image was considered during analysis. The resolution is a measure of output quality of the image usually given as pixels per linear $\mathrm{mm}$; many pixels per $\mathrm{mm}$ give a high resolution image with good quality while fewer pixels per mm give a low resolution image of comparatively poor quality.

4.3.1. Thresholding. The images were thresholded so that a grey value can be assigned to air voids and aggregate within the asphalt mixture. Threshold is the technique applied in image analysis to characterize the components of the mixture. It converts the representative grey scale of a component into a value [13]. This value is then the only value associated with an element and so it can be identified in the mixture. These different grey values are applied to distinguish the microstructural components of the asphalt mixture. Grey 


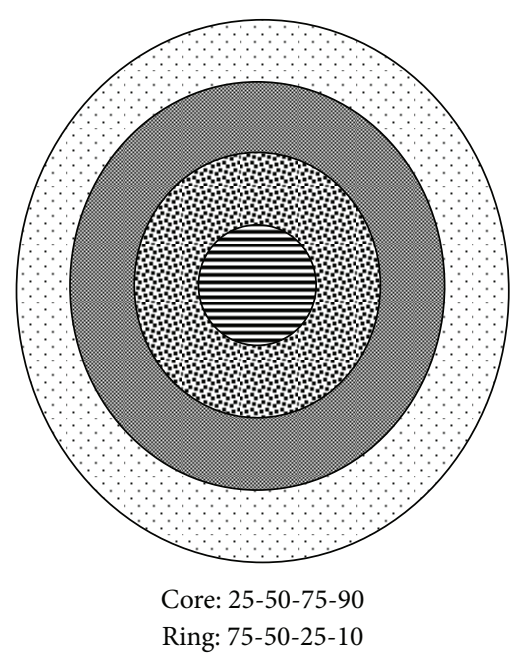

(a)

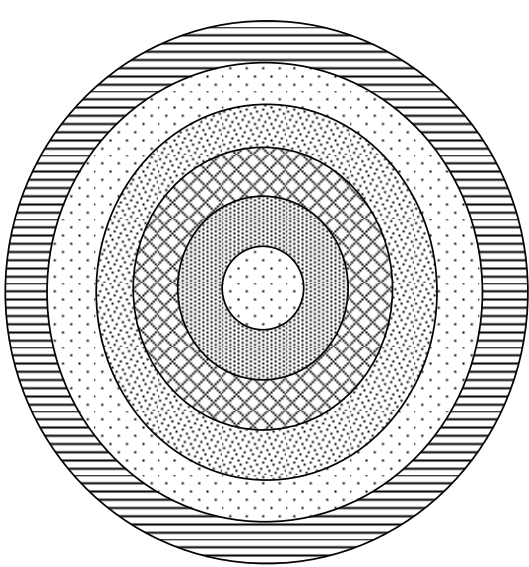

Core: $25-50-75-100-125-140$

Ring: $125-100-75-50-25-10$

(b)

FIGURE 6: Virtual cutting area in the radial direction for specimens 1 and 2.

value changes with the density of different components in the mixture and it has different values. Once the grey value is selected the image can be analysed for mixture components. Grey level distribution for complex asphalt mixture and air voids after threshold is shown in Figure 4.

A grey level (36 in this case) was selected such that it gave air voids value in comparison with the value obtained from laboratory density method (BS EN 12697-6:2003). This did not consider the small pores/voids within aggregate particles. The same grey level was then used for the remaining analysis [14].

The results of the air void analysis were obtained as follows.

Specimen 0 (100/100). From image analysis of both virgin and reclaimed asphalt mixtures there is high air void content at the top and bottom of the specimen compared to the middle part (Figure 5). RA-Mix shows slightly higher air voids at the top section. As noted, this may be due to difficulty in compacting the specimens with reclaimed asphalt. Some researchers have excluded the top and bottom $5 \mathrm{~mm}$ of specimen in the analysis to omit the effect of surface voids distribution [6]. However, this reduced the exact size of the specimens under consideration.

Specimens 1 (150/100) and 2 (150/150). To investigate the homogeneity of the trimmed and cored specimens, the air void distribution analysis was performed in vertical and radial directions for specimens 1 and 2 . The specimens were virtually cut in the radial direction (Figure 6). The core and ring were then analysed for air void content distribution. Figures 7 and 8 show the air voids distribution throughout the specimens for the core and ring for specimens 1 and 2. Specimen 1 has a higher air void content in the middle compared to the top and bottom parts which will result in a higher air void content in a trimmed section compared to the design. The air voids in specimen 2 are more uniformly distributed from top to bottom with higher values towards both ends. This shows homogeneous properties after coring and trimming of 10 to $25 \mathrm{~mm}$ at the top, bottom, and outer sections of the specimen. This is in confirmation with the air void content determined from laboratory standard sealed specimen as presented in Table 2 . While, void content in specimens 1 and 2 of 100/100 ratio is higher and lower, respectively, than the designed values.

It can be summarised from the data that compacted specimens of different height to diameter ratio give different air voids distribution. Specimens compacted using procedures number 0 and $2(H / D=1)$ have resulted in a uniform air voids distribution throughout the specimen, while specimens compacted following procedure number $1(H / D=1.5)$ resulted in a nonuniform distribution of air voids. This is probably due to nonuniform compaction from procedure number 1 though the target density achieved from procedure 1 was similar to the density obtained from procedures 0 and 2 .

The standard deviation of the air void distribution for each core and ring sections was also determined (Table 4). The data shows the value after optimization is comparatively lower for the specimen produced with $150 / 150$. Nonuniform air voids distributions within the cut sections increase as the core diameter was reduced from $100 \mathrm{~mm}$ to $25 \mathrm{~mm}$.

Therefore, the specimens' procedure 2 which consists of trimming the core (100/100) from designed specimen $(150 / 150)$ was selected to produce test specimen of homogenous air void distribution.

\section{Optimisation Study to Achieve the Target Density}

In order to obtain test specimen with a fixed value of target density, the specimens of (150/150) were compacted at different densities (100\%, 95\%, and $90 \%)$ of the original target density, respectively. This was done to achieve a compaction standard for predicting the density of the cores (100/100). The concept was to obtain a relationship between the air void 


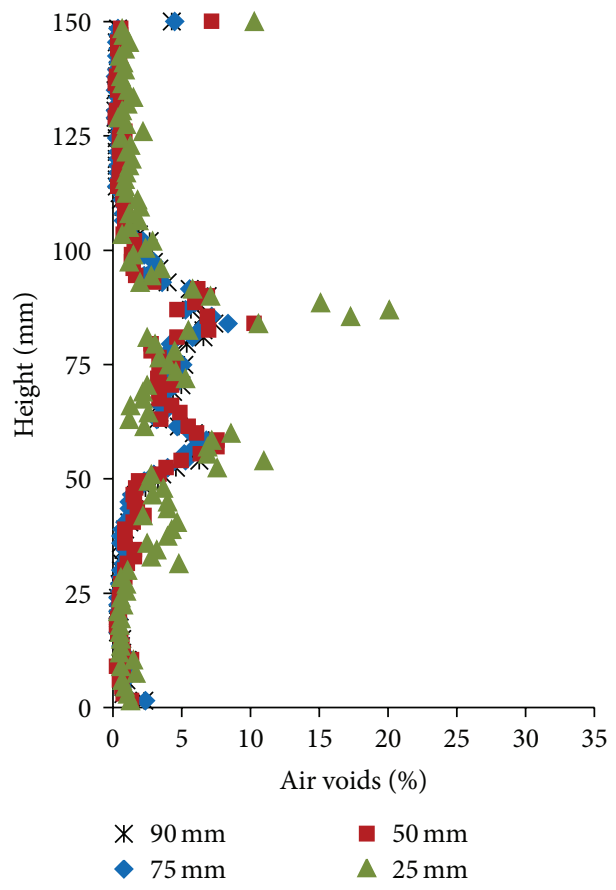

(a)

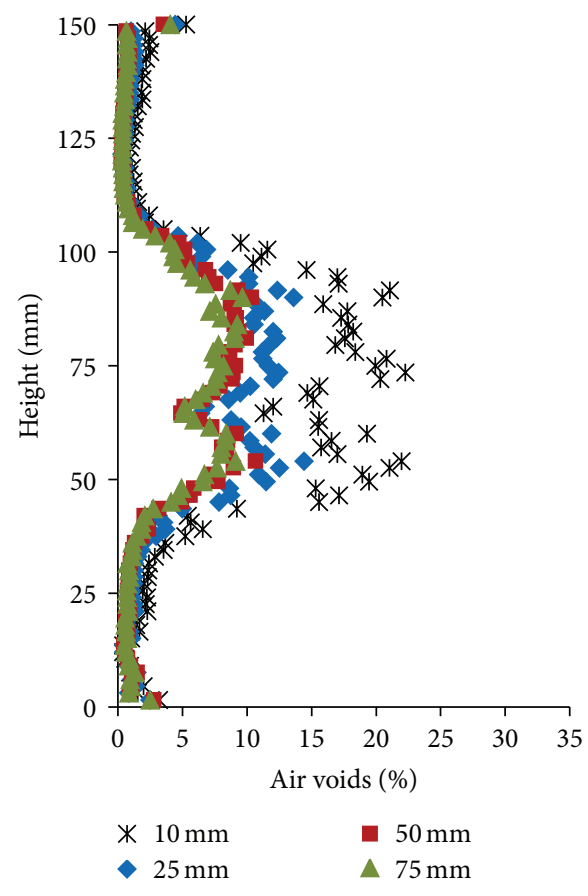

(b)

FIGURE 7: Air voids distribution within the virtual cut of (a) core and (b) ring for specimen 1.

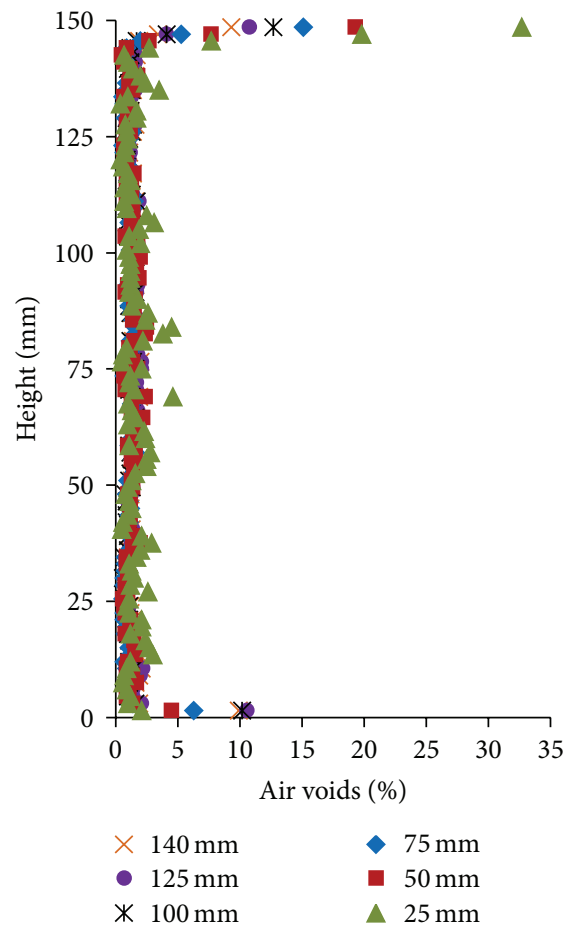

(a)

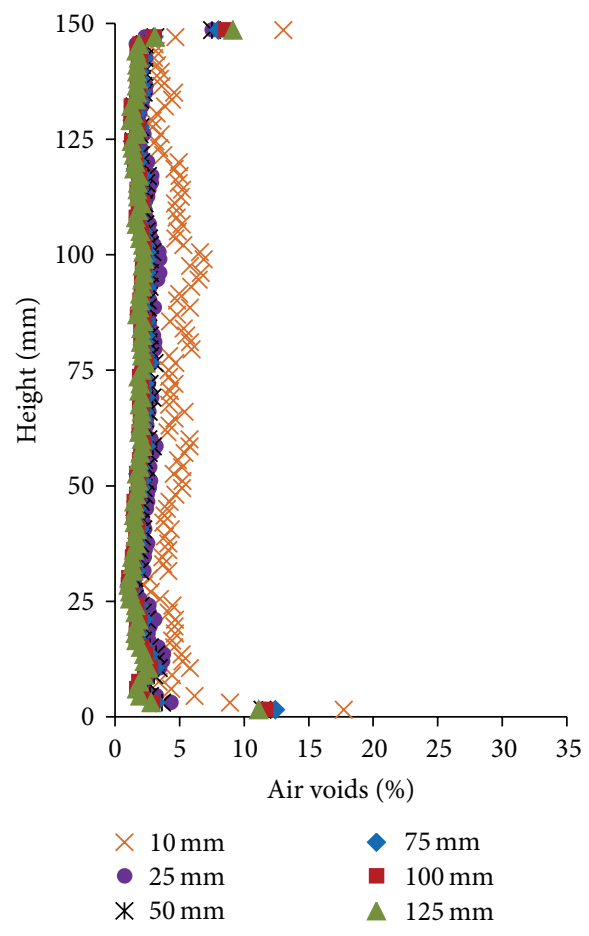

(b)

FIGURE 8: Air voids distribution within the virtual cut of (a) core and (b) ring for specimen 2. 


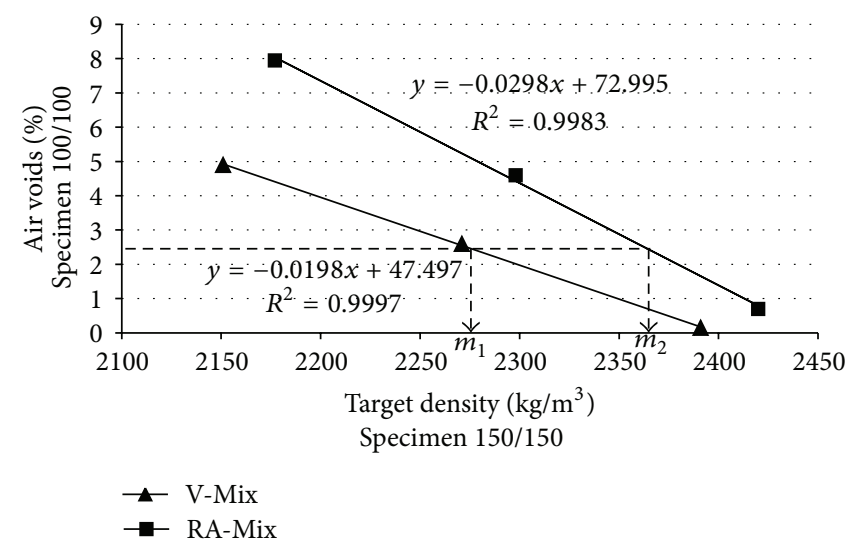

FIGURE 9: Relationships of the desired air voids content of the 150/150 specimen to be compacted and the target density to be set on the gyratory compactor.

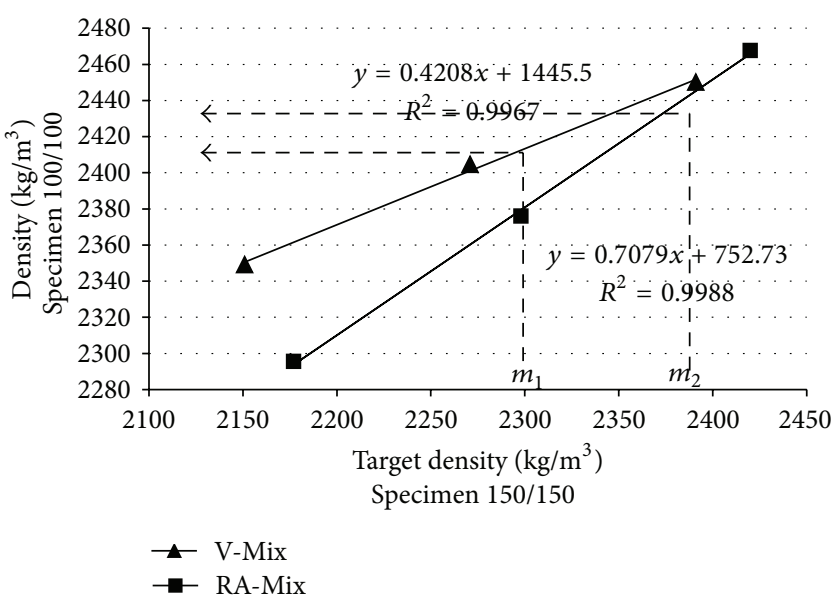

FIGURE 10: Relationships of the density of the cores (120/100) and the target compacted density of specimen 150/150.

content and density of the cores and the target density of the 150/150 specimen. Two replicates for each target density were prepared for taking the average. Table 5 summarises the density and air voids content of the specimens before and after coring which were determined using laboratory sealed specimen method. The relationships of the air voids content and the average density to the target compacted density are plotted in Figures 9 and 10.

Linear relationships were obtained for air voids content and density of both the mixtures with $R$-squared $\left(R^{2}\right)$ values close to 1 . The relationship in Figure 9 was then used to estimate the target density for compacting specimen 150/150 in order to obtain a core of 100/100 with homogeneous air voids content of $2.6 \%$. The achieved density of $150 / 150$ for both V-Mix and RA-Mix was $m_{1}=2267 \mathrm{~kg} / \mathrm{m}^{3}$ and $m_{2}=$ $2362 \mathrm{~kg} / \mathrm{m}^{3}$, respectively. The target density of the cores was determined from Figure 10, using the estimated values.

From the estimated values, specimens of (150/150) were produced for both V-Mix and RA-Mix. The cores of (100/100) were cut and trimmed from the specimens and their density and air voids content were determined from the laboratory. The air voids distribution was then analysed throughout the cores from the X-ray images. The image analysis results for V-Mix and RA-Mix are presented in Figures 11 and 12, respectively.

\section{Summary}

The core of 100/100 for V-Mix (virgin mixture) and RA-Mix (30\% of reclaimed asphalt) has a homogenous air voids distribution throughout the core and the ring analyses. However, a small variation in the air voids content can be observed at the middle of the core of $25 \mathrm{~mm}$ for both mixtures as shown in Figures 9(a) and 10(a). This occurs only at a certain level of height, while at others the air void contents values are the same through the height of specimens. The authors assume that the middle core section of the specimen gets less effect of compaction (higher air voids area) compared to the sections that are close to the circumference due to the effect of mould confinement during compaction. Therefore, the small diameter of the analysed core $(25 \mathrm{~mm})$ has resulted in higher ratio of the air voids content to the total area of the core section. 

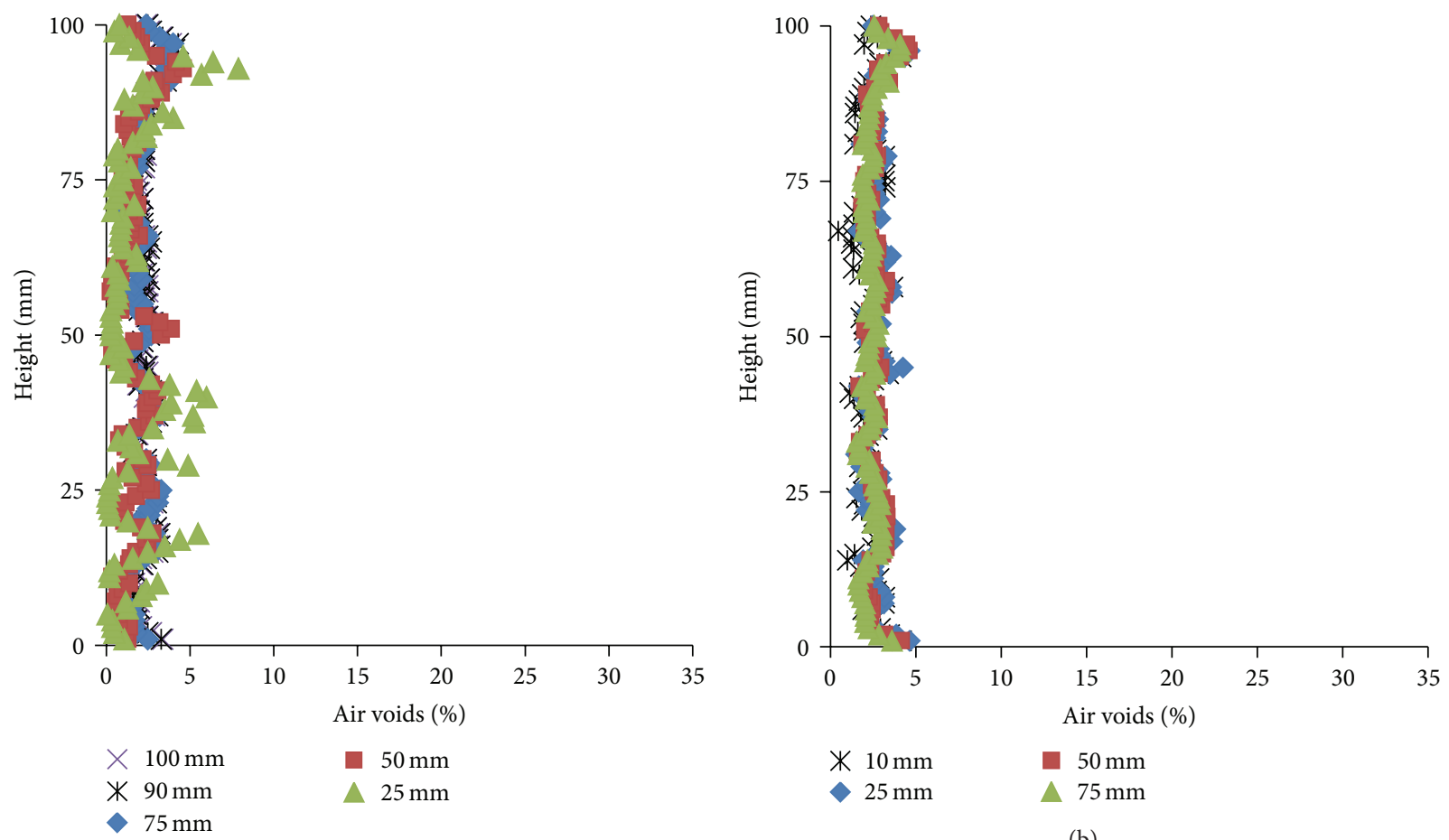

(a)

(b)

Figure 11: Air voids distribution within the virtual cut of (a) core and (b) ring for V-Mix with the air voids content of $2.6 \%$ and density of $2392 \mathrm{~kg} / \mathrm{m}^{3}$.

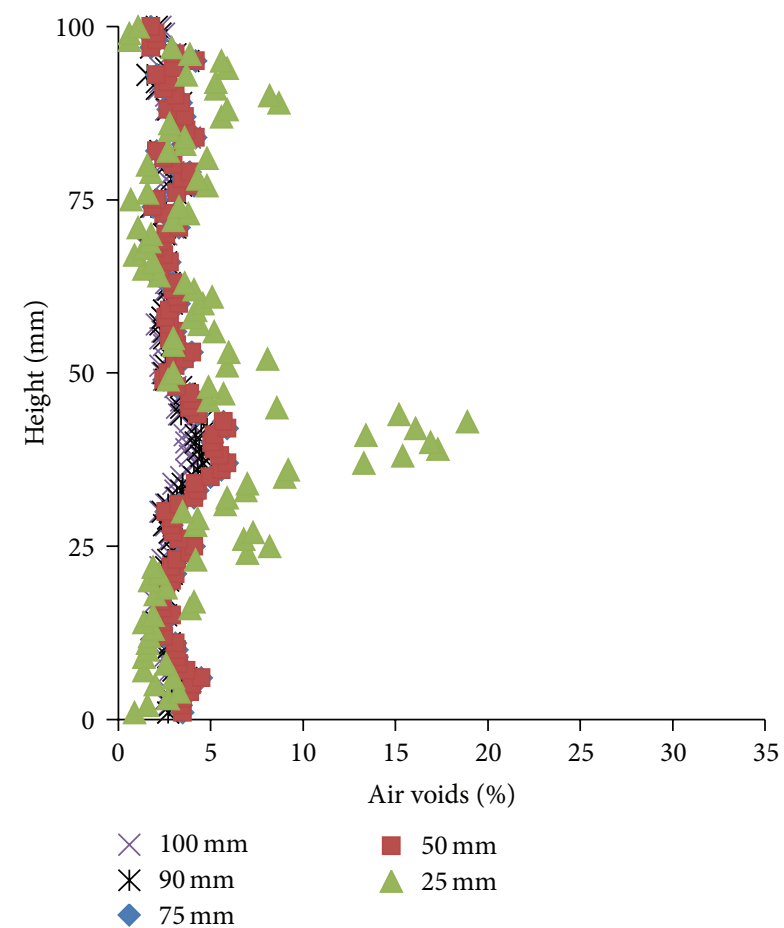

(a)

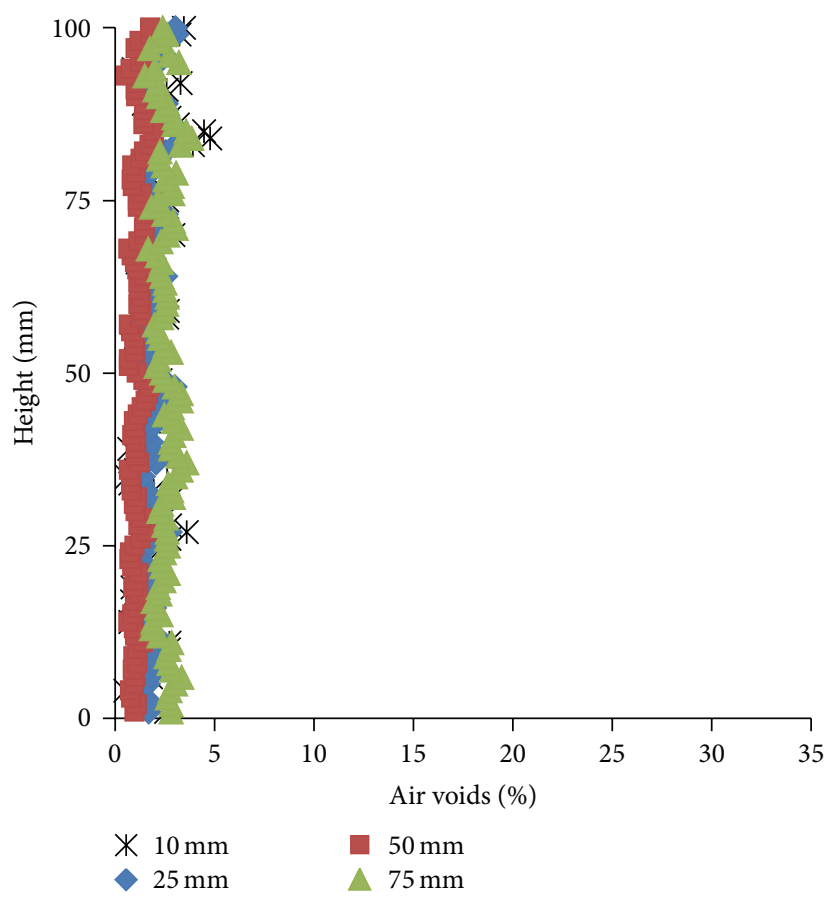

(b)

FIGURE 12: Air voids distribution within the virtual cut of (a) core and (b) ring for RA-Mix with the air voids content of $2.6 \%$ and density of $2420 \mathrm{~kg} / \mathrm{m}^{3}$. 
TABLE 4: Standard deviation for the core and ring analysis.

\begin{tabular}{lccccccccccccc}
\hline \multirow{2}{*}{ Specimen type } & \multicolumn{1}{c}{ Core diameter $(\mathrm{mm})$} & \multicolumn{4}{c}{ Ring size $(\mathrm{mm})$} \\
& 140 & 125 & 100 & 90 & 75 & 50 & 25 & 10 & 25 & 50 & 75 & 100 & 125 \\
\hline 1 & - & - & - & 2.2 & 2.1 & 2.2 & 3.5 & 7.5 & 4.6 & 3.5 & 3.2 & - & - \\
2 & 1.2 & 1.4 & 1.5 & - & 1.6 & 2 & 3.8 & 1.9 & 1.2 & 1.1 & 1.3 & 1.2 & 1.2 \\
RA-Mix & - & - & 0.55 & 0.67 & 0.94 & 0.94 & 3.93 & 0.82 & 0.51 & 0.3 & 0.45 & - & - \\
V-Mix & - & - & 0.5 & 0.58 & 0.72 & 0.9 & 1.69 & 0.68 & 0.63 & 0.56 & 0.5 & - & - \\
\hline
\end{tabular}

TABLE 5: Details density and air voids content for optimization.

\begin{tabular}{|c|c|c|c|c|c|c|c|}
\hline \multirow{2}{*}{ Type } & \multirow{2}{*}{$\begin{array}{c}\text { Max. density } \\
\left(\mathrm{kg} / \mathrm{m}^{3}\right)\end{array}$} & \multicolumn{2}{|c|}{ Gyratory compacted specimen $(150 / 150)$} & \multicolumn{4}{|c|}{ After coring (laboratory determined density of $100 / 100$ ) } \\
\hline & & $\begin{array}{l}\text { Target density } \\
\quad\left(\mathrm{kg} / \mathrm{m}^{3}\right)\end{array}$ & $\begin{array}{l}\text { Target air } \\
\text { voids (\%) }\end{array}$ & $\begin{array}{l}\text { Lab. density } \\
\quad\left(\mathrm{kg} / \mathrm{m}^{3}\right)\end{array}$ & $\begin{array}{l}\text { Av. density } \\
\left(\mathrm{kg} / \mathrm{m}^{3}\right)\end{array}$ & $\begin{array}{l}\text { Air voids } \\
\quad(\%)\end{array}$ & $\begin{array}{l}\text { Av. air voids } \\
(\%)\end{array}$ \\
\hline \multirow{6}{*}{ V-Mix } & \multirow{6}{*}{2454} & \multirow{2}{*}{2391} & \multirow{2}{*}{2.6} & 2449 & \multirow{2}{*}{2450} & 0.2 & \multirow{2}{*}{0.15} \\
\hline & & & & 2451 & & 0.1 & \\
\hline & & \multirow{2}{*}{2271} & \multirow{2}{*}{7.5} & 2404 & \multirow{2}{*}{2404.5} & 2.0 & \multirow{2}{*}{2.6} \\
\hline & & & & 2405 & & 3.2 & \\
\hline & & \multirow{2}{*}{2151} & \multirow{2}{*}{12.3} & 2293 & \multirow{2}{*}{2349} & 6.6 & \multirow{2}{*}{4.9} \\
\hline & & & & 2405 & & 3.2 & \\
\hline \multirow{6}{*}{ RA-Mix } & \multirow{6}{*}{2485} & \multirow{2}{*}{2420} & \multirow{2}{*}{2.6} & 2465 & \multirow{2}{*}{2467.5} & 0.8 & \multirow{2}{*}{0.7} \\
\hline & & & & 2470 & & 0.6 & \\
\hline & & \multirow{2}{*}{2298} & \multirow{2}{*}{7.5} & 2373 & \multirow{2}{*}{2376} & 4.9 & \multirow{2}{*}{4.6} \\
\hline & & & & 2379 & & 4.6 & \\
\hline & & \multirow{2}{*}{2177} & \multirow{2}{*}{12.4} & 2292 & \multirow{2}{*}{2295.5} & 8.1 & \multirow{2}{*}{7.95} \\
\hline & & & & 2299 & & 7.8 & \\
\hline
\end{tabular}

\section{Conclusion}

This paper summarises a laboratory investigation into producing specimens with homogeneous properties. Based on the results, the following conclusions are drawn.

(i) The gyratory compaction method can be used to manufacture a homogeneous test specimen for virgin asphalt mixture and those containing up to $30 \%$ of reclaimed asphalt.

(ii) X-ray CT scanning can be applied to study nondestructively the microstructure of compacted asphalt specimens and homogeneity of the air voids distribution.

(iii) For the same air void content, a gyratory compacted specimen with $H / D$ ratio of $1(100 / 100$ and $150 / 150)$ produces uniformly distributed air voids throughout the specimen compared to specimens produced with $H / D$ ratio of $1.5(150 / 100)$.

(iv) A proposed protocol consists of mixing; coring and trimming the $150 / 150$ specimen can be applied to obtain a core of 100/100 with homogeneous air voids distribution.

(v) Results show that it is possible to get homogenous specimen with a maximum $H / D$ ratio of 1.2 .

\section{Conflict of Interests}

The authors declare that there is no conflict of interests regarding the publication of this paper.

\section{Acknowledgments}

The authors thank Mick Winfield and Dr. James Grenfell of Nottingham Transportation Engineering Centre, University of Nottingham, for their help in testing of specimens.

\section{References}

[1] BS EN, "Bituminous mixtures. Test methods for hot mix asphalt. Specimen preparation by gyratory compactor," BS EN 12697-31, British Standard, London, UK, 2007.

[2] D. Lo Presti, N. A. Hassan, G. Airey, and A. Collop, "Fundamental characterisation of reclaimed asphalts: the importance of testing homogeneous specimens," Road Material and Pavement Design, vol. 14, supplement 1, pp. 120-131, 2013.

[3] P. M. Muraya, "Homogeneous test specimens from gyratory compaction," International Journal of Pavement Engineering, vol. 8, no. 3, pp. 225-235, 2007.

[4] L. Tashman, W. Linbing, and S. Thyagarajan, "Microstructure characterization for modeling HMA behaviour using imaging technology," Road Materials and Pavement Design, vol. 8, no. 2, pp. 207-238, 2007.

[5] M. Krishna and K. Rajagopal, "A brief review of the uses and modelling of bitumen from ancient to modern times," Internal 
Report, Department of Mechanical Engineering, Texas A\&M University, College Station, 2002.

[6] H. M. Zelelew, A. T. Papagiannakis, and E. Masad, "Application of digital image processing for asphalt concrete mixture images," in Proceedings of the 12th International Conference of International Association for Computer Methods and Advances in Geomechanics, Goa, India, October 2008.

[7] R. Khan and A. C. Collop, "The use of X-ray computed tomography to characterize microdamage in asphalt," Road Materials and Pavement Design, vol. 11, pp. 89-109, 2010.

[8] L. B. Wang, H. S. Paul, T. Harman, and D. 'Angelo J, "Characterization of aggregates and asphalt concrete using X-ray tomography," Journal of the Association of Asphalt Paving Technologists, vol. 73, pp. 467-500, 2004.

[9] E. Masad, B. Muhunthan, N. Shashidhar, and T. Harman, "Internal structure characterization of asphalt concrete using image analysis," Journal of Computing in Civil Engineering, vol. 13, no. 2, pp. 88-95, 1999.

[10] E. Masad, V. K. Jandhyala, N. Dasgupta, N. Somadevan, and N. Shashidhar, "Characterization of air void distribution in asphalt mixes using X-ray computed tomography," Journal of Materials in Civil Engineering, vol. 14, no. 2, pp. 122-129, 2002.

[11] L. Tashman, E. Masad, B. Peterson, and H. Saleh, "Internal structure analysis of asphalt mixes to improve the simulation of superpave gyratory compaction to field conditions," Journal of the Association of Asphalt Paving Technologists, vol. 70, pp. 605-645, 2001.

[12] J. de Visscher, K. Mollenhauer, J. Raaberg, T. Gabet, and R. Khan, "Mix design and performance of asphalt at mixing plant-reroad deliverable," 2011, http://re-road.fehrl.org/.

[13] R. Khan, Quantification of microstructural damage in asphalt [Ph.D. thesis], University of Nottingham, Nottingham, UK, 2010.

[14] X Tek, X-Ray Computed Tomography Operation Manual, X Tek, Germany, 2005. 

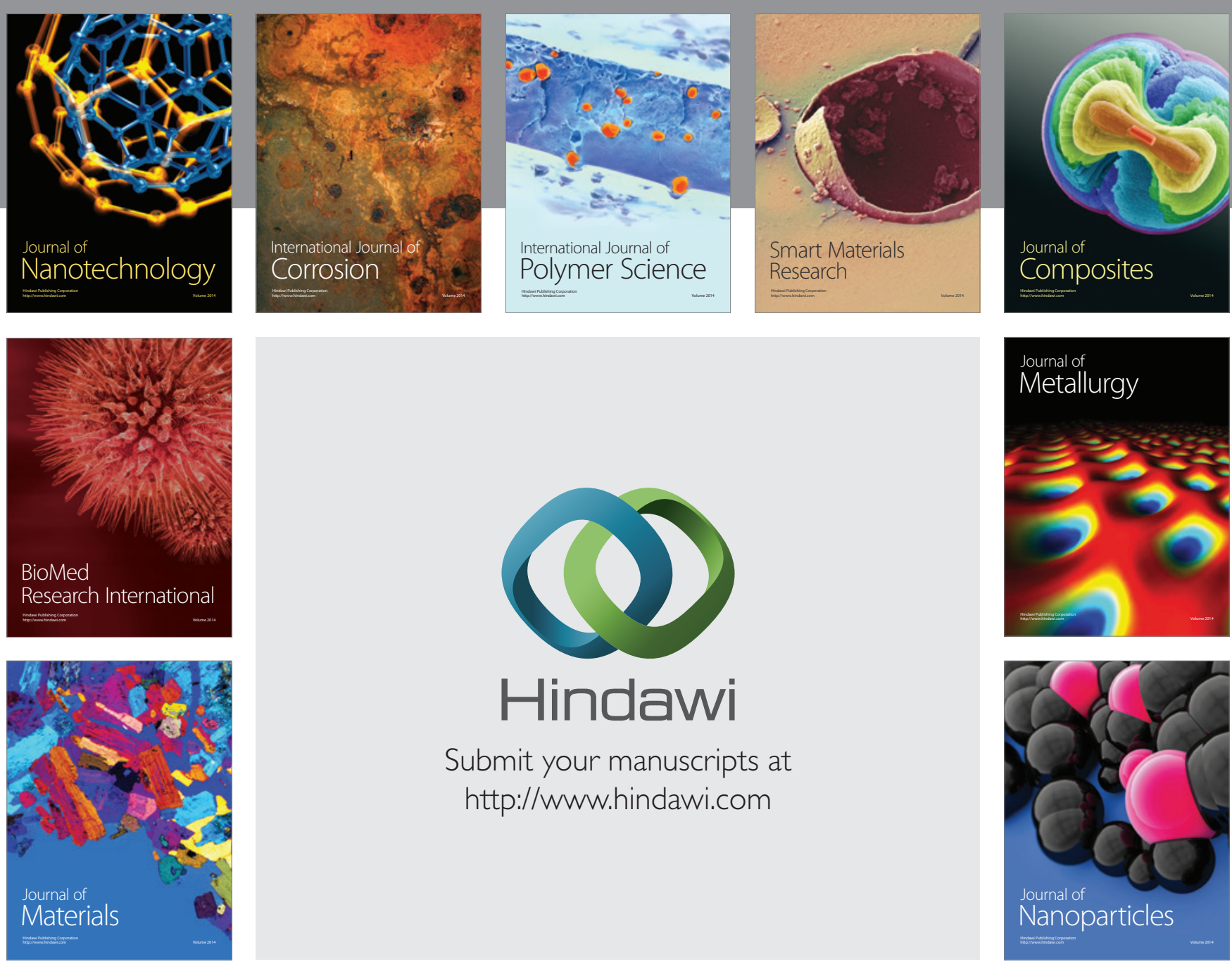

Submit your manuscripts at http://www.hindawi.com
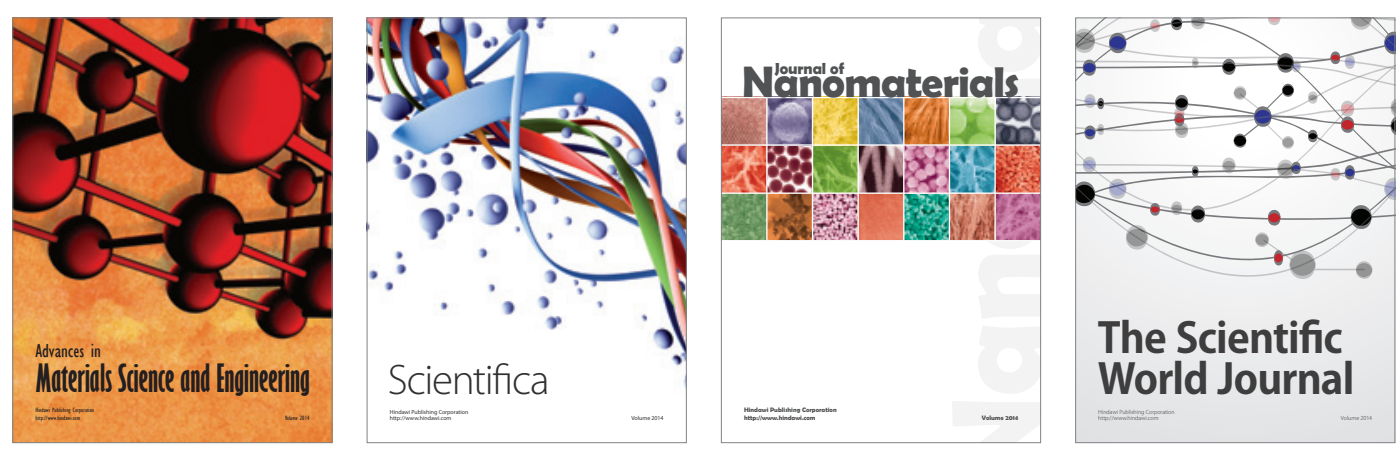

\section{The Scientific World Journal}
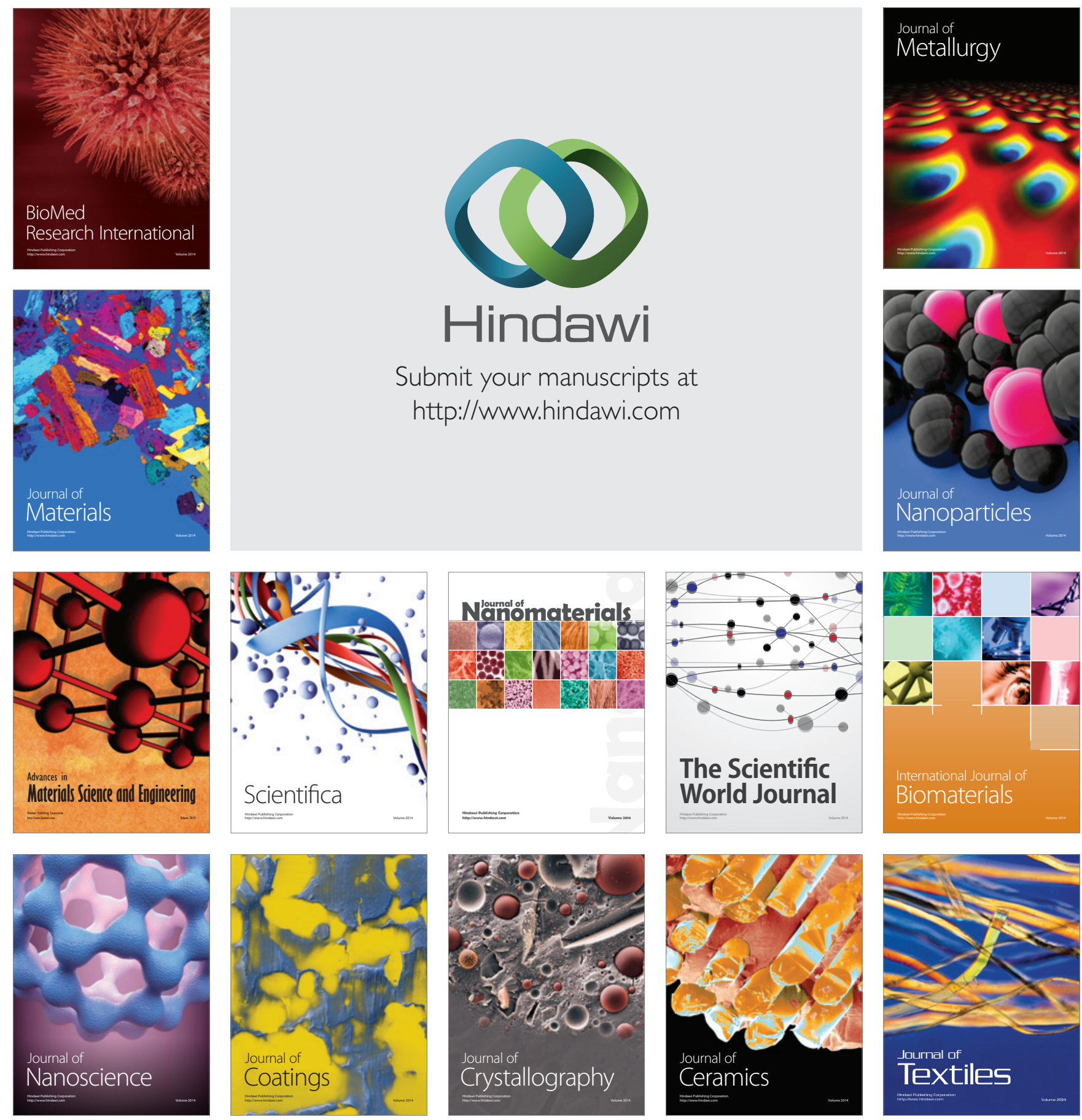